\title{
PRESENCE AND SIGNIFICANCE OF MICRO-ORGANISMS IN OPEN FRACTURES
}

\author{
Sambit Acharya ${ }^{1}$, Mallika Sengupta $^{2}$, Soma Sarkar ${ }^{3}$, Atreyi Chakroborty ${ }^{4}$, Aniruddha Sengupta ${ }^{5}$, Manideepa Sengupta ${ }^{6}$
}

1Postgraduate Trainee, Department of Orthopaedics, Medical College and Hospital, Kolkata, West Bengal.

${ }^{2}$ Assistant Professor, Department of Microbiology, KPC Medical College and Hospital, Kolkata, West Bengal.

${ }^{3}$ Assistant Professor, Department of Microbiology, Medical College, Kolkata, West Bengal.

${ }_{4}^{4}$ Assistant Professor, Department of Microbiology, Medical College, Kolkata, West Bengal.

5 Professor, Department of Orthopaedics, Medical College and Hospital, Kolkata, West Bengal.

${ }^{6}$ Professor and HOD, Department of Microbiology, Medical College, Kolkata, West Bengal.

\section{BACKGROUND}

ABSTRACT

Open fractures with bony injuries should be fixed urgently to prevent further injury and pain. Consideration of skin and soft tissue injuries along with the presence of infection by myriad of bacteria pose a threat by delaying wound healing and worsening of prognosis.

The aim of this study was to find out the different types of micro-organisms contaminating open fractures along with their antimicrobial susceptibility pattern.

\section{MATERIALS AND METHODS}

The study was a prospective observational study conducted in Medical College, Kolkata for a period of one and a half years (March 2016 to August 2017). Cases selected in the Department of Orthopaedics and Casualty were those who had open fractures of duration of presentation of less than 1 day. Wound swabs were taken from the depth of the wound and sent to the Department of Microbiology for isolation, identification and antimicrobial susceptibility testing of the causative micro-organisms. Repeat swabs were taken on 3rd, 5th, 7th and 10th days after presentation during each debridement.

\section{RESULTS}

A total number of 400 patients were included in this study during the period of 1.5 years. The mechanism of injury was mostly road or rail traffic accidents in 232 (58\%) cases. Maximum number of open fractures were sustained in leg, comprising 169 (42.25\%) followed by forearm of 106 (26.5\%) cases. The most common organisms were Staphylococci, Enterobacteriaceae and Pseudomonas. Staphylococcus and Enterococcus were highly susceptible to vancomycin and linezolid. The Gram negative organisms were susceptible to imipenem, meropenem and colistin.

\section{CONCLUSION}

It is pertinent to know the microbial organisms in open fractures for judicial use of antibiotics only after proper culture and sensitivity report to prevent emergence of more resistant strains of pathogens.

\section{KEYWORDS}

Contamination, Staphylococcus, Wound, Sensitivity.

HOW TO CITE THIS ARTICLE: Acharya S, Sengupta M, Sarkar S, et al. Presence and significance of micro-organisms in open fractures. J. Evolution Med. Dent. Sci. 2018;7(14):1782-1785, DOI: 10.14260/jemds/2018/402

\section{BACKGROUND}

Open fractures are always a challenge in orthopaedics. Firstly, there are bony injuries that have in most cases resulted from high velocity(1) trauma and requires to be fixed urgently to prevent further injury and pain. Then there are the considerations of skin and soft tissue injuries that take a long time and a multidisciplinary approach to heal. Complicating all these is the presence of infection by myriad of bacteria, delaying wound healing and worsening prognosis by causing a variety of dreaded complications like skin and soft tissue infections, gangrenous and pyogenic myonecrosis, osteomyelitis and non-union.(2)

'Financial or Other Competing Interest': None.

Submission 18-02-2018, Peer Review 16-03-2018,

Acceptance 22-03-2018, Published 02-04-2018.

Corresponding Author:

Dr. Soma Sarkar,

Assistant Professor,

Department of Microbiology, Medical College,

Kolkata 88 College Street, Kolkata-700073, West Bengal.

E-mail: drdssarkar@gmail.com

DOI: $10.14260 /$ jemds $/ 2018 / 402$
To prevent the occurrence of infective complications antibiotics are used, wound irrigation and debridement are done. Open fractures are characterised by soft tissue disruption at the fracture site increasing the risk of complications such as infections, non-union and delayed healing. Risk of infection depends on injury severity, wound contamination, extent of soft tissue damage, interval between onset and presentation and treatment received at presentation. Treatment received at presentation depends on its timing from onset, i.e. trauma and includes copious wound irrigation, debridement and antibiotic administration.(2)

The suitability of antibiotic to be administered on presentation should depend on the antibiotic sensitivity of the microflora contaminating the open fracture. It should not be a best guess or traditionally accepted antibiotic, but one chosen after sound clinical considerations of the more prevalent bacteria contaminating open wounds in the community and their antibiotic sensitivity pattern. This in turn depends on the commensal micro-organisms, (3) colonising our body and on environmental micro-organisms acting as contaminants. The risk of infection in open fractures is increased manifold by the vascular compromise occurring 
at the site and the presence of necrotic debris creating an ideal niche for the growth of microbes. The issue of necrotic debris can be tackled with meticulous debridement, ${ }^{(4)}$ but vascular compromise remains a menace. While these infections can be partially tackled by the host immune system, poor vascularity reduces host defence. Commensurate with the increasing tissue injury involved, complication risk increases with grade. For example, Type I fractures are at $0 \%-2 \%$ risk of developing infection, Type II have a $2 \%$ - $12 \%$ risk, while Type III have a $10 \%-50 \%$ risk. ${ }^{(5)}$ This can be further complicated in immune-compromised host.(5) To combat this, antibiotics form an essential weapon. The choice of antibiotics is as important as its timely and regular administration, dosage and duration. The chosen antibiotic should have a broad spectrum of coverage, acting suitably against both Gram positive and Gram negative microorganisms and may include a combination of antibiotics. Unless controlled suitably, infectious complications become a very bad prognostic factor, compromising both bone and soft tissue healing. The spread of infection is a potent risk to the patients, which may necessitate amputation later. The haematogenous spread of infection may also be fatal. Hence, infections need to be suitably and aggressively controlled. For this, it is necessary to know the organisms commonly present in the wound.

The aim of this study was to find out the different types of micro-organisms contaminating open fractures along with their antimicrobial susceptibility pattern.

\section{MATERIALS AND METHODS}

The study was a prospective observational study. After obtaining ethical clearance from the institute and informed consent from the patients, this study was conducted in Medical College and Hospital, Kolkata for a period of one and a half years (March 2016 to August 2017). Adult patients who had open fractures of duration of presentation less than 1 day were selected as cases in the Department of Orthopaedics and Casualty. Patients having closed fractures or with compromised immunity, suffering from diabetes mellitus, those who had received treatment elsewhere and those having a duration of more than 1 day between trauma and presentation were excluded from the study.

With all aseptic precautions, material was collected from deep parts of the wound with a sterile swab stick and put in a sterile test tube. It was sent immediately to the Department of Microbiology for culture and sensitivity testing. Repeat swabs were taken on the 3rd, 5th, 7th and 10th days after presentation during each debridement.

Wound swabs were taken from the depth of the wound and were sent to the Department of Microbiology, Medical College, Kolkata for further processing. After performing a direct microscopy of the Gram stained smear, the pus was inoculated on blood agar, MacConkey agar and Thioglycolate broth. Isolation, identification of the micro-organisms and their antimicrobial susceptibility were done using standard techniques and interpretation was done according to Clinical and Laboratory Standard Institute (CLSI) guidelines version 2016.(6)

\section{RESULTS}

Four hundred patients presenting with open fractures in the Orthopaedics Department of Medical College and Hospital,
Kolkata were chosen by consecutive sampling and after proper informed consent, samples and clinical information were collected from them. A total of 290 (72.5\%) patients were male and $110(27.5 \%)$ patients were female. Maximum patients (34\%) belonged to the age group of 38 - 48 years followed by 28 - 38 years (24.25\%) and $18-28$ years (22.75\%) (Table 1).

\begin{tabular}{|c|c|c|}
\hline Age Group (Years) & Count & Percent \\
\hline $18-28$ & 91 & $22.75 \%$ \\
\hline $28-38$ & 97 & $24.25 \%$ \\
\hline $38-48$ & 136 & $34.0 \%$ \\
\hline $48-58$ & 56 & $14.0 \%$ \\
\hline $58-68$ & 15 & $3.75 \%$ \\
\hline $68-78$ & 5 & $1.25 \%$ \\
\hline Total & $\mathbf{4 0 0}$ & $\mathbf{1 0 0 . 0} \%$ \\
\hline Table 1. Shows the Age Distribution of the Patients \\
Included \\
\hline
\end{tabular}

The mechanism of injury was road or rail traffic accident in $232(58 \%)$ cases. This was followed by trauma due to fall in $90(22.5 \%)$ cases, crush injury in $39(9.75 \%)$ cases and direct blow in 31 (7.75\%) cases. Other mechanisms including blast injuries and certain machine injuries (those without crush) constituted $8(2 \%)$ cases. Maximum number of patients $293(73.25 \%)$ sustained their injuries on the roadside/ railway track. This was followed by injuries sustained in the field while playing/ farming comprising 36 (9\%) cases and injuries at home 17 (4.25\%) cases. Injuries at other places comprised of $54(13.5 \%)$ cases and mostly included workplace related injuries. Maximum number of open fractures were sustained in leg, comprising 169 (42.25\%) followed by forearm 106 (26.5\%) cases. Almost equal number of injuries were sustained at the hand and the foot, $42(10.5 \%)$ and $33(8.25 \%)$ respectively. Thigh wounds comprised of 31 (7.75\%) cases followed by arm 13 (3.25\%). The torso and the pelvis were the least frequent sites of open fractures, comprising $4(1 \%)$ and $2(0.5 \%)$ cases respectively.

Open fractures were classified by their Gustilo-Anderson (GA) types.(7) Most cases were type II injuries followed by type I and type III injuries (Table 2). Type III injuries included crush injuries and traumatic amputations.

\begin{tabular}{|c|c|c|c|c|}
\hline \multirow[t]{2}{*}{\begin{tabular}{|c|} 
Gustilo \\
Anderson Type
\end{tabular}} & \multicolumn{3}{|c|}{ Time of Presentation (Hours) } & \multirow[t]{2}{*}{ Total } \\
\hline & $<1$ hours & 2 - 6 hours & $\begin{array}{l}6-24 \\
\text { hours }\end{array}$ & \\
\hline & Count (\%) & Count (\%) & Count (\%) & Count $(\%)$ \\
\hline GA Type I & $\begin{array}{c}33 \\
(25.6 \%)\end{array}$ & $\begin{array}{c}52 \\
(40.3 \%)\end{array}$ & $\begin{array}{c}44 \\
(34.1 \%)\end{array}$ & $\begin{array}{c}129 \\
(32.25 \%)\end{array}$ \\
\hline GA Type II & $\begin{array}{c}49 \\
(29.22 \%) \\
\end{array}$ & $\begin{array}{c}67 \\
(39.88 \%) \\
\end{array}$ & $\begin{array}{c}52 \\
(31.0 \%) \\
\end{array}$ & $\begin{array}{c}168 \\
(42 \%)\end{array}$ \\
\hline GA Type III & $\begin{array}{c}31 \\
(30.1 \%) \\
\end{array}$ & $\begin{array}{c}42 \\
(40.8 \%) \\
\end{array}$ & $\begin{array}{c}30 \\
(29.1 \%) \\
\end{array}$ & $\begin{array}{c}103 \\
(25.75 \%) \\
\end{array}$ \\
\hline Total & $\begin{array}{c}113 \\
(8.25 \%)\end{array}$ & $\begin{array}{c}161 \\
(0.25 \%)\end{array}$ & $\begin{array}{c}126 \\
(31.5 \%)\end{array}$ & $\begin{array}{c}400 \\
(100 \%)\end{array}$ \\
\hline \multicolumn{5}{|c|}{$\begin{array}{l}\text { Table 2. Shows the Gustilo-Anderson Types along with the } \\
\text { Time of Presentation }\end{array}$} \\
\hline
\end{tabular}

Among a total of 400 open fractures 298 (74.5\%) were culture positive, while the rest 102 (25.5\%) were culture negative. Among these 157 cases were infected primarily with a single bacterial species, in 104 cases two bacteria were present, while in 37 cases there were three bacteria 
contaminating the wound. Among the total of 1472 organisms isolated, Staphylococcus aureus was most frequent $349(23.71 \%)$ followed by coagulase negative Staphylococci 273 (18.55\%), Klebsiella species 200 (13.59\%), Pseudomonas aeruginosa 167 (11.34\%), Escherichia coli 143 (9.71\%), Enterococcus species 113 (7.68\%) and Acinetobacter species $60(4.08 \%)$. Other organisms (167 or $11.34 \%)$ isolated were Streptococcus pyogenes, other Streptococcus species, Morganella and Providencia. Staphylococcus and Enterococcus were highly susceptible to vancomycin, linezolid and gentamycin (Table 3). The Gram negative organisms like Escherichia coli, Klebsiella, Pseudomonas and Acinetobacter were susceptible to imipenem, meropenem and colistin (Table 4).

\begin{tabular}{|c|c|c|c|}
\hline $\begin{array}{l}\text { Antimicrobial } \\
\text { Agent }\end{array}$ & $\begin{array}{l}\text { Staphylococcus } \\
\text { aureus }(\mathrm{n}=349)\end{array}$ & $\begin{array}{c}\text { CoNS } \\
(n=273)\end{array}$ & $\begin{array}{l}\text { Enterococcus } \\
\text { spp. }(\mathrm{n}=113)\end{array}$ \\
\hline Penicillin & 0 & 0 & 0 \\
\hline Cefoxitin & $80(22.9 \%)$ & $\begin{array}{c}92 \\
(33.7 \%)\end{array}$ & NA \\
\hline Amikacin & 289 (82.8\%) & $\begin{array}{c}230 \\
(84.2 \%) \\
\end{array}$ & NA \\
\hline Gentamicin & $268(76.8 \%)$ & $\begin{array}{c}218 \\
(79.8 \%)\end{array}$ & $102(90.3 \%)$ \\
\hline Ciprofloxacin & $84(24.1 \%)$ & $\begin{array}{c}42 \\
(15.4 \%)\end{array}$ & $18(15.9 \%)$ \\
\hline Levofloxacin & $113(32.4 \%)$ & $\begin{array}{c}51 \\
(18.7 \%)\end{array}$ & $30(26.5 \%)$ \\
\hline Doxycycline & $144(41.3 \%)$ & $\begin{array}{c}158 \\
(57.9 \%)\end{array}$ & $104(92.0 \%)$ \\
\hline \begin{tabular}{|c|} 
Trimethoprim/ \\
Sulfamethoxazole \\
\end{tabular} & 207 (59.3\%) & $\begin{array}{c}183 \\
(67.0 \%) \\
\end{array}$ & NA \\
\hline Clindamycin & $248(71.1 \%)$ & $\begin{array}{c}194 \\
(71.1 \%)\end{array}$ & NA \\
\hline Erythromycin & 198 (56.7\%) & $\begin{array}{c}156 \\
(57.1 \%)\end{array}$ & $82(72.6 \%)$ \\
\hline Linezolid & $336(96.3 \%)$ & $\begin{array}{c}260 \\
(95.2 \%)\end{array}$ & $108(95.6 \%)$ \\
\hline Vancomycin & 349 (100\%) & $\begin{array}{c}273 \\
(100 \%)\end{array}$ & $109(96.5 \%)$ \\
\hline \multicolumn{4}{|c|}{$\begin{array}{c}\text { Table 3. Shows the Susceptibility of Gram Positive } \\
\text { Organisms Isolated }\end{array}$} \\
\hline
\end{tabular}

$\mathrm{NA}=$ Not Applicable.

\begin{tabular}{|c|c|c|c|c|}
\hline 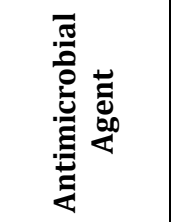 & 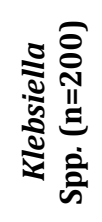 & : & 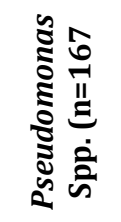 & 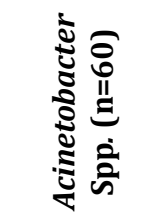 \\
\hline Ampicillin & 0 & 0 & NA & $\mathrm{NA}$ \\
\hline $\begin{array}{l}\text { Piperacillin/ } \\
\text { Tazobactam }\end{array}$ & $\begin{array}{c}192 \\
(96 \%)\end{array}$ & $\begin{array}{c}141 \\
(98.6 \%)\end{array}$ & $\begin{array}{c}154 \\
(92.2 \%)\end{array}$ & 58 (96.6\%) \\
\hline Ceftriaxone & $\begin{array}{c}130 \\
(65 \%)\end{array}$ & $\begin{array}{c}108 \\
(75.5 \%)\end{array}$ & NA & NA \\
\hline Ceftazidime & NA & NA & 0 & $12(20 \%)$ \\
\hline Imipenem & $\begin{array}{c}196 \\
(98 \%) \\
\end{array}$ & $\begin{array}{c}140 \\
(97.9 \%) \\
\end{array}$ & $\begin{array}{c}160 \\
(95.8 \%) \\
\end{array}$ & $60(100 \%)$ \\
\hline Meropenem & $\begin{array}{c}196 \\
(98 \%) \\
\end{array}$ & $\begin{array}{c}140 \\
(97.9 \%) \\
\end{array}$ & $\begin{array}{c}158 \\
(94.6 \%) \\
\end{array}$ & $60(100 \%)$ \\
\hline Amikacin & $\begin{array}{c}144 \\
(72 \%)\end{array}$ & $\begin{array}{c}116 \\
(81.1 \%)\end{array}$ & $\begin{array}{c}144 \\
(86.2 \%)\end{array}$ & $58(96.6 \%)$ \\
\hline Gentamicin & $\begin{array}{c}114 \\
(57 \%)\end{array}$ & $\begin{array}{c}110 \\
(76.9 \%)\end{array}$ & $\begin{array}{c}121 \\
(72.4 \%) \\
\end{array}$ & $58(96.6 \%)$ \\
\hline
\end{tabular}

\begin{tabular}{|c|c|c|c|c|}
\hline $\begin{array}{c}\text { Ciprofloxaci } \\
\mathrm{n}\end{array}$ & $\begin{array}{c}110 \\
(55 \%)\end{array}$ & $84(58.7 \%)$ & $\begin{array}{c}74 \\
(44.3 \%)\end{array}$ & $46(76.6 \%)$ \\
\hline Levofloxacin & $\begin{array}{c}110 \\
(55 \%)\end{array}$ & $93(65 \%)$ & $\begin{array}{c}84 \\
(50.3 \%)\end{array}$ & $60(100 \%)$ \\
\hline Doxycycline & $\begin{array}{c}120 \\
(60 \%)\end{array}$ & $\begin{array}{c}119 \\
(83.2 \%)\end{array}$ & $\mathrm{NA}$ & $41(68.3 \%)$ \\
\hline Polymyxin B & $\begin{array}{c}200 \\
(100 \%)\end{array}$ & $\begin{array}{c}143 \\
(100 \%)\end{array}$ & $\begin{array}{c}167 \\
(100 \%)\end{array}$ & $60(100 \%)$ \\
\hline $\begin{array}{c}\text { Trimethopri } \\
\text { m/Sulfamet } \\
\text { hoxazole }\end{array}$ & $\begin{array}{c}132 \\
(66 \%)\end{array}$ & $\begin{array}{c}116 \\
(81.1 \%)\end{array}$ & $\mathrm{NA}$ & $48(60 \%)$ \\
\hline \multicolumn{5}{|c|}{ Table 4. Shows the Susceptibility of Gram Negative } \\
Organisms Isolated \\
\hline
\end{tabular}

$\mathrm{NA}=$ Not applicable.

Of the total 298 contaminated wounds, 33 showed subsequent wound infection by secondary contaminant. None of the wounds that were primarily not infected became secondarily infected. In (29/33) cases, the secondarily infected wound showed presence of at least one of the primary organisms. Most of the wound infections were with Escherichia coli (9/33) followed by Pseudomonas species (7/33).

The quantitative and qualitative data obtained from the study were analysed using appropriate statistical tests of significance (Binary Logistic Regression and Linear Regression) and ' $p$ ' values were calculated in each case. The relation between type of injury and presence of contamination was found to be statistically significant $(\mathrm{p}=$ 0.009). The relation between time of presentation and presence of contamination was found to be statistically significant $(p=0.002)$.

\section{DISCUSSION}

In a study by Gustilo RB et al, it was found that in open fractures in addition to adequate debridement, irrigation and definitive wound care, parenteral administration of appropriate antibiotics within three hours after injury helped to prevent wound sepsis. Initial wound cultures of 158 open fracture wounds revealed bacterial growth in $70.3 \%$ of which 86 were Gram positive, 57 were Gram negative and 32 yielded mixed bacterial growth.(2) In a prospective study by Alonge et al, it was seen within six hours of injury, single organism isolates were commonly found, whilst after 48 hours a mixed or poly-microbial organism load were isolated. In $90 \%$ of the positive isolates, the organisms isolated from the superficial and the deep swabs were the same. The antibiotic sensitivity pattern of all the isolates showed that pefloxacin, ciprofloxacin and ceftriaxone were more effective compared to cefuroxime and amoxycillin, which had substantial resistance to most of the isolates.(8) A study by Ikem et al was done to determine the pattern of bacterial isolates and antibiotic sensitivity profile in open fractures. Fifty-nine patients with open fractures of the lower limb long bones were studied. The majority of the cases being Gustilo and Anderson types II 21 (35.6\%) and IIIA 16 (27.1\%). The infection rate was 45.8\%. Staphylococcus aureus 13 (25\%) and Coagulase negative staphylococci (CoNS) 14 (26.9\%) were the commonest organisms isolated. The commonest Gram negative rods that were isolated from the wounds were Proteus mirabilis 9 (17.3\%) and Pseudomonas aeruginosa 8 (15.4\%). Multiple organisms were commonly isolated. While all the organisms isolated showed very good sensitivity to 
gentamicin, cloxacillin and ofloxacin. Most of the organisms were resistant to penicillin, ampicillin and tetracycline.(9) In this study among 400 patients, 157 cases were infected primarily with a single bacterial species, in 104 cases two organisms were present and in 37 cases there were three organisms. Among the total number of organisms isolated (1472), Staphylococcus aureus was most frequent 349 (23.71\%) followed by coagulase negative Staphylococci 273 (18.55\%), Klebsiella species 200 (13.59\%), Pseudomonas aeruginosa 167 (11.34\%), Escherichia coli 143 (9.71\%), Enterococcus species 113 (7.68\%), Acinetobacter species 60 $(4.08 \%)$ and other organisms (11.34\%) like Streptococcus pyogenes, other Streptococcus species, Morganella and Providencia.

A prospective study by Ojo et al in sixty patients having open fractures, the initial culture of wound swabs taken on the day of presentation was positive in 41 (68.3\%) patients. Of these, 19 (46.3\%) yielded one bacteria isolate, 17 (41.5\%) yielded two and $5(12.2 \%)$ yielded three, making a total of 68 organisms. The most common organism was Staphylococcus aureus. 11 (18.3\%) patients developed wound infections, all of which were polymicrobial. In 10 (90.9\%) of these, the microbial isolate of the final wound swab included at least one organism that was present in the initial wound culture. No patient with an initial negative culture went on to develop a wound infection.(10) A retrospective cohort study was conducted by Otchwemah $\mathrm{R}$ and group. They were of the opinion that the bacterial contamination of soft tissues and bone in open fractures led to an infection rate of up to $50 \%$. Pathogens and their resistance against therapeutic agents change with time and vary in different regions. Among their 123 patients $45(37 \%)$ were classified as $\mathrm{I}^{\circ}, 45(37 \%)$ as $\mathrm{II}^{\circ}$ and $33(27 \%)$ as III $^{\circ}$. Lower leg (34\%) was the most commonly injured location. An antibiotic prophylaxis was administered to 109 patients (89\%). In 107 of them (98\%), a cephalosporin alone or cephalosporin combination was given. In 35 of the patients (28\%), microbiological samples were taken of the fracture site. Wound cultures were positive in 21 patients $(60 \%)$. In this study, most cases were injury GA type II and presented in 2 - 6 hours after injury. The mechanism of injury was mostly road or rail traffic accidents in 232 (58\%) cases. Maximum number of open fractures was sustained in leg, comprising 169 (42.25\%) followed by forearm 106 (26.5\%) cases.

Quoting Bergman, "no antibiotic can replace proper surgical management,(11)" and although the microbial and pharmacological arms race will continue with growing bacterial resistance, bacteria are unlikely to develop resistance to surgeon's knife. In addition to prophylactic antibiotic administration, wound debridement and irrigation are important procedures for preventing open fracture infection. The goal of open fracture surgical debridement is the excision of environmental debris, devitalised soft tissue and bone as well as irrigation of the wound to reduce bacterial load. Proper and judicial use of antibiotic prophylaxis should be given along with debridement.

The limitations of this study were that the study was done in an urban area, not representing the rural population and those who presented late could not be included. Furthermore, the study did not have a control group. Duration of stay in hospital may also have had an impact on contaminating bacteria due to presence of nosocomial organisms.

\section{CONCLUSION}

This study showed that most open fractures were primarily contaminated by one or multiple organisms and require an active regimen of wound irrigation, debridement and antibiotic administration for the control of infection and reduction of complications. The most common contaminating organisms were Staphylococcus, Pseudomonas and Enterobacteriaceae. The result of this study will perhaps act as a guide in choosing the most effective antibiotic in cases of open fractures in teaching hospitals in the region and future studies are likely to be based on this research. However, large multicentric studies and meta-analysis are required to accurately predict the nature and duration of antibiotics required in different situations. These should also address the role of commensal and nosocomial bacteria in wound contamination.

\section{REFERENCES}

[1] Court-Brown CM, Bugler KE, Clement ND, et al. The epidemiology of open fractures in adults. A 15-year review. Injury 2012;43(6):891-7.

[2] Gustilo RB. Use of antimicrobials in the management of open fractures. Arch Surg 1979;114(7):805-8.

[3] Alonge TO, Salawu SA, Adebisi AT, et al. The choice of antibiotic in open fractures in a teaching hospital in a developing country. Int J Clin Pract 2002;56(5):353-6.

[4] Pollak AN. Timing of débridement of open fractures. J Am Acad Orthop Surg 2006;14(10 Spec No.):S48-51.

[5] Bowen TR, Widmaier JC. Host classification predicts infection after open fracture. Clin Orthop Relat Res 2005;(433):205-11.

[6] Patel JB. Clinical and Laboratory Standards Institute. Performance standards for antimicrobial susceptibility testing, 2016.

[7] ATLS Subcommittee, American College of Surgeons' Committee on Trauma, International ATLS working group. Advanced trauma life support (ATLS®): the ninth edition. J Trauma Acute Care Surg 2013;74(5):1363-6.

[8] Alonge TO, Ogunlade SO, Salawu SA, et al. Microbial isolates in open fractures seen in the accident and emergency unit of a teaching hospital in a developing country. West Afr J Med 2002;21(4):302-4.

[9] Ikem IC, Oginni LM, Bamgboye EA, et al. The bacteriology of open fractures in Ile-Ife, Nigeria. Niger J Med 2004;13(4):359-65.

[10] Ojo OD, Oluwadiya KS, Ikem IC, et al. Superficial swab cultures in open fracture management: insights from a resource-poor setting. J Wound Care 2010;19(10):432-8.

[11] Bergman BR. Antibiotic prophylaxis in open and closed fractures: a controlled clinical trial. Acta Orthop Scand 1982;53(1):57-62. 